Article

\title{
Synergistic Enhancement of Cancer Therapy Using a Combination of Ceramide and Docetaxel
}

\author{
Li-Xia Feng, Min Li, Yong-Jun Liu, Shao-Mei Yang and Na Zhang * \\ Department of Pharmaceutics, College of Pharmacy, Shandong University, 44 West Culture Road, \\ Ji'nan 250012, China; E-Mails: fenglixia0910@126.com (L.-X.F.); sdlimin@sina.cn (M.L.); \\ o-oliuyongjun@163.com (Y.-J.L.); yangshaomei01@163.com (S.-M.Y.) \\ * Author to whom correspondence should be addressed; E-Mail: zhangnancy9@sdu.edu.cn; \\ Tel.: +86-531-8838-2015; Fax: +86-531-8838-2548.
}

Received: 23 January 2014; in revised form: 19 February 2014 / Accepted: 21 February 2014 / Published: 10 March 2014

\begin{abstract}
Ceramide (CE)-based combination therapy (CE combination) as a novel therapeutic strategy has attracted great attention in the field of anti-cancer therapy. The principal purposes of this study were to investigate the synergistic effect of $\mathrm{CE}$ in combination with docetaxel (DTX) (CE + DTX) and to explore the synergy mechanisms of CE + DTX. The 3-(4,5-Dimethylthiazol-2-yl)-2,5-diphenyltetrazolium bromide (MTT) and combination index (CI) assay showed that simultaneous administration of CE and DTX with a molar ratio of $0.5: 1$ could generate the optimal synergistic effect on murine malignant melanoma cell $(\mathrm{B} 16, \mathrm{CI}=0.31)$ and human breast carcinoma cell $(\mathrm{MCF}-7$, $\mathrm{CI}=0.48$ ). The apoptosis, cell cycle, and cytoskeleton destruction study demonstrated that $\mathrm{CE}$ could target and destruct the microfilament actin, subsequently activate Caspase- 3 and induce apoptosis. Meanwhile, DTX could target and disrupt the microtubules cytoskeleton, leading to a high proportion of cancer cells in G2/M-phase arrest. Moreover, CE plus DTX could cause a synergistic destruction of cytoskeleton, which resulted in a significantly higher apoptosis and a significantly higher arrest in G2/M arrest comparing with either agent alone $(p<0.01)$. The in vivo antitumor study evaluated in B16 tumor-bearing mice also validated the synergistic effects. All these results suggested that $\mathrm{CE}$ could enhance the antitumor activity of DTX in a synergistic manner, which suggest promising application prospects of CE + DTX combination treatment.
\end{abstract}

Keywords: ceramide; docetaxel; combination therapy; anti-cancer; synergy mechanisms 


\section{Introduction}

Cancer is the leading cause of deaths worldwide and chemotherapy is one of the major trends on cancer therapy $[1,2]$. However, the problems of mono-chemotherapy, such as inadequacy of efficacy, drug resistance and systemic toxicity, would not be completely solved in a short time. Moreover, the administration doses of cytotoxic drugs cannot be limitlessly increased [3]. Based on this situation, combination therapy arose in response and was expected to achieve high therapeutic efficacy at lower drug dose [4]. Among various kinds of combination therapy strategies, combinations of multiple cytotoxic drugs have attracted significant attention [3]. For example, bevacizumab/gemcitabine on ovarian cancer [5], gemcitabine/taxane on metastatic breast cancer [6,7], and cisplatin/taxane [8] and cisplatin/gemcitabine [9] on non-small cell lung cancer have been widely studied and used. In spite of moderate increase in the therapeutic efficacy, combining multiple cytotoxic drugs for cancer therapy might simultaneously lead to a potential danger of drug interaction toxicity [10], cross-resistance [11] and a compromise in quality of life. Therefore, it is urgent to develop a novel combination therapy strategy for cancer treatment.

When evaluated in preclinical studies, some biologic agents plus cytotoxic drugs exhibit additive or synergistic activity without excessive toxicity, providing a promising direction for combination therapy [12]. For example, interleukin-2 (IL-2) and/or alpha-interferon ( $\alpha$-IFN) have been widely used in clinical study to combine with cisplatin, vinblastine, or 5-fluorouracil for the patient with metastatic cancer, which resulted in a synergistic therapeutic efficacy [13]. Among different biologic agents, ceramide (CE) showed great potential in designing novel combination therapy strategies [14]. $\mathrm{CE}$ is a naturally occurring sphingolipid, which is derived intracellularly by hydrolysis of the lipid sphingomyelin or by de novo synthesis through $N$-acylation of sphinganine $[15,16]$. CE has been newly realized as important intracellular signaling molecules that mediate diverse cellular effects, of which programmed cell growth, differentiation, and death have attracted significant interests in recent years $[17,18]$. Although the exact mechanism has not fully elucidated, CE has been identified as a putative anti-cancer therapeutic agent from a therapeutic perspective due to its important role in apoptosis [19]. Considering endogenous CE can subsequently be further metabolized by the enzyme glucosylceramide synthase (GCS) to yield glucosylceramide (GC) which does not have any proapoptotic activities and oppositely induce the serious multi-drug resistance (MDR), exogenous CE was introduced to preclinical study of cancer treatment [20]. It has been reported that, a polymeric nanoparticles, based on poly(ethylene oxide)-poly(epsilon caprolactone) (PEO-PCL), was prepared to co-deliver exogenous CE and Paclitaxel (PTX) [21]. Against a PTX-resistant ovarian cancer cell (SKOV-3TR), the combination of CE with PTX was found to raise PTX sensitivity of the MDR cells to the same level as non-MDR cells, which showed a 100 -fold increase in therapeutic efficacy as compared to PTX alone. These exciting results showed great potential for combination of exogenous $\mathrm{CE}$ and cytotoxic drugs.

As this approach gathers more attention, it is becoming important to consider clinical issues such as choice of cytotoxic drugs, optimized dosing schedule, and mechanisms of synergy in order to identify the most effective combination treatment regimen [22,23]. Despite the supportive preclinical data, it is still unknown whether exogenous CE could be combined with different cytotoxic drugs to show synergistic therapeutic effects on various cancer treatments because of the heterogeneity of different 
cancers and the diverse anti-cancer mechanisms of different antineoplastic drugs. Therefore, there is an urgent need to investigate and develop a comparatively comprehensive strategy on CE-based combination therapy (CE combination).

In present study, the in vitro anti-proliferation effects of exogenous CE combining with three traditionally and widely used anti-cancer drugs: docetaxel (DTX), PTX, and Doxorubicin (DOX) were correspondingly evaluated on four different cancer cell lines: murine malignant melanoma cell line (B16), human breast carcinoma cell line (MCF-7), human ovarian carcinoma cell line (SKOV3), and human hepatocellular carcinoma cell line (HepG2), respectively, by 3-(4,5-Dimethylthiazol-2-yl)-2,5diphenyltetrazolium bromide (MTT) assay. Then the combination index (CI) was further calculated to analyze whether there is a synergistic effect between $\mathrm{CE}$ and the chosen anti-cancer drug. To optimize the dosing schedule, the experiments of screening for optimal combination ratio and sequence of administration were subsequently carried out by MTT assay and CI assay. Cell apoptosis induction, Caspase-3 activity, cell cycle arrest and cytoskeleton destruction were systematically studied to exploit the mechanisms of synergy between CE and DTX. In order to verify the in vivo synergy effects, the in vivo antitumor efficacy of CE + DTX was also experimented.

\section{Results}

\subsection{Effects of CE Combination on Cell Proliferation (MTT Assay)}

The anti-proliferation effects of CE combination (CE + DTX, CE + PTX, or CE + DOX) at molar ratio 1:1 was evaluated at various concentrations by MTT assay on B16, SKOV3, MCF-7, and HepG2 cells, respectively.

The results of the cell viability with different treatments were shown in Figure 1. In the case of B16 and MCF-7 cells, comparing with CE, DTX, PTX, or DOX, CE combination (CE + DTX, CE + PTX and $\mathrm{CE}+\mathrm{DOX}$ ) showed much lower cell viabilities at all given concentrations (except $0.5 \mu \mathrm{M}$ ), respectively, indicating a strong potential for combination treatment. For SKOV3 cells, only $\mathrm{CE}+\operatorname{DOX}(5-40 \mu \mathrm{M})$ showed cytotoxicity enhancements compared with either agent alone $(p<0.05)$. In addition, $\mathrm{CE}+\mathrm{DOX}, \mathrm{CE}+\mathrm{PTX}$, but not CE + DTX, generated significantly higher anti-proliferation effects on HepG2 cells $(p<0.05)$ at some of the experimented concentrations.

In order to qualitatively evaluate whether the combination of CE with DTX, PTX, or DOX could generate synergistic antiproliferative effects, CI, a commonly used evaluation index, was calculated [24-26]. CI values at 50\% growth inhibition points were calculated based on the results of MTT tests and the CI values were shown in Figure 2. CI values of CE + DTX were 0.47 on B16 cells and 0.71 on MCF-7 cells, respectively, indicating that the synergistic antiproliferative effect of CE + DTX was preliminarily established on B16 and MCF-7 cells. Similar synergistic effect was observed in CE + PTX combination treatment, with the CI values were 0.54 on B16 cells, 0.63 on MCF-7 cells and 0.55 on HepG2 cells, respectively, indicating that the combination of CE with PTX might also be promising. Meanwhile, no obvious synergy was found for CE + DOX and even slight antagonism was observed on B16 cells, which warned that the combination of CE with DOX might not be an optimal option for cancer treatment under such given conditions. 
In comparison with the other anti-cancer drugs, DTX was most synergistic with CE on B16 cells for the $\mathrm{CI}$ value at $50 \%$ growth inhibition point was lowest $(\mathrm{CI}=0.47$, Figure 2$)$, therefore, $\mathrm{CE}+\mathrm{DTX}$ was chosen for further study. Correspondingly, the positive cell lines (cells showed synergistic antiproliferative effect): B16 and MCF-7 were chosen as model cells.

Figure 1. Effects of different treatments on cell viabilities (\% from untreated control) of B16, SKOV3, MCF-7 and HepG2 cells $(n=3)$. Cells were treated with CE, DTX, PTX, DOX, or 1:1 combination molar ratio of CE plus one of the three anti-tumor drugs, respectively, at a series of concentration from 0.5 to $40 \mu \mathrm{M}$. (A-1-A-4) The comparative test among CE, DTX, and CE + DTX; (B-1-B-4) The comparative test among CE, PTX and CE + PTX; (C-1-C-4) The comparative test among CE, DOX and CE + DOX. $* p<0.05, * * p<0.01$, statistically significant difference between $\mathrm{CE}$ and combination treatment (CE + DTX, CE + PTX, or CE + DOX, respectively); ${ }^{\#} p<0.05,{ }^{\# \#} p<0.01$, statistically significant difference between DTX and combination treatment (CE + DTX, CE + PTX, or CE + DOX, respectively).

B16
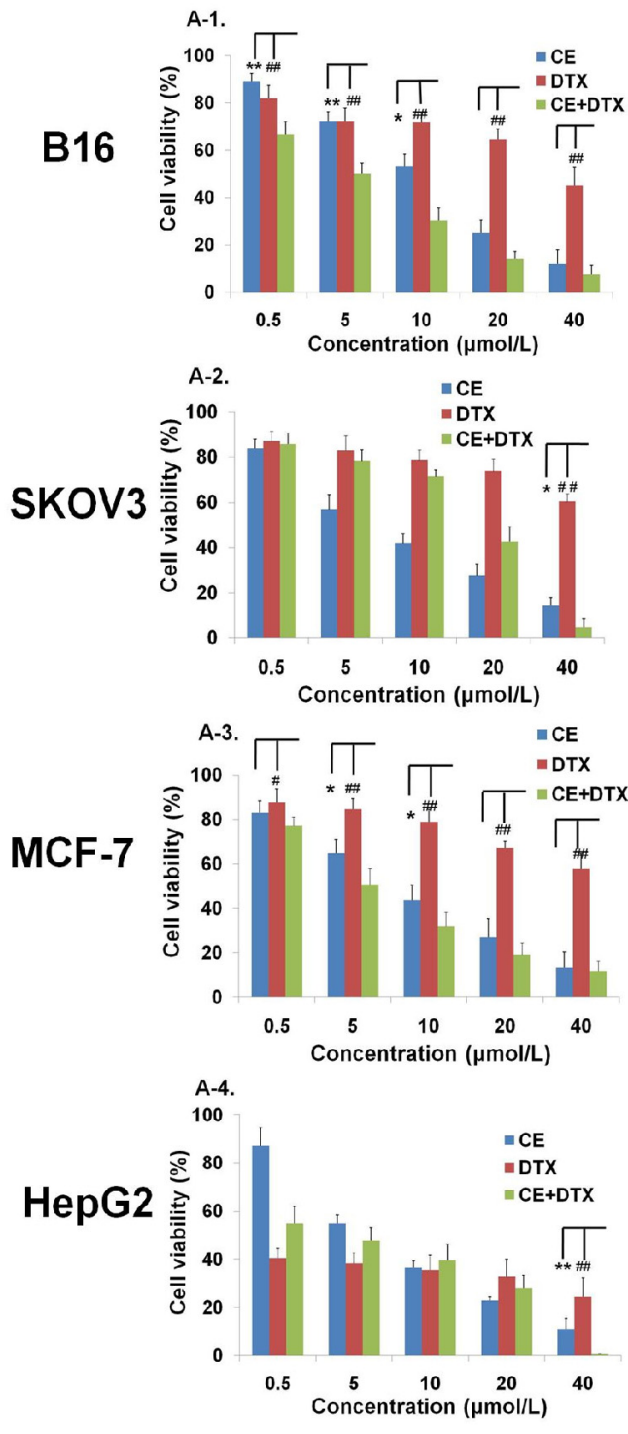
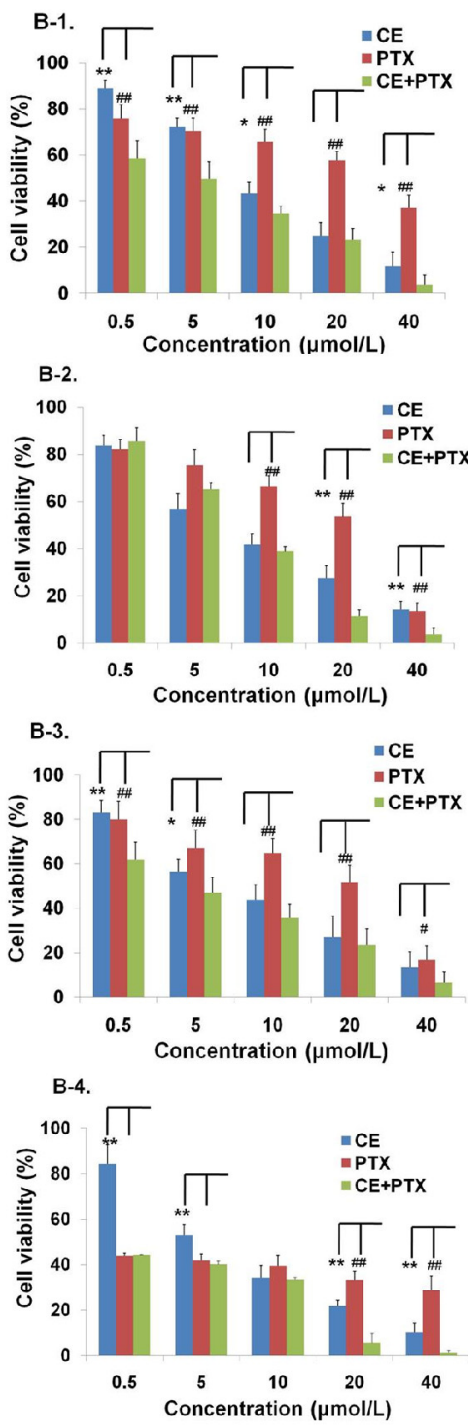
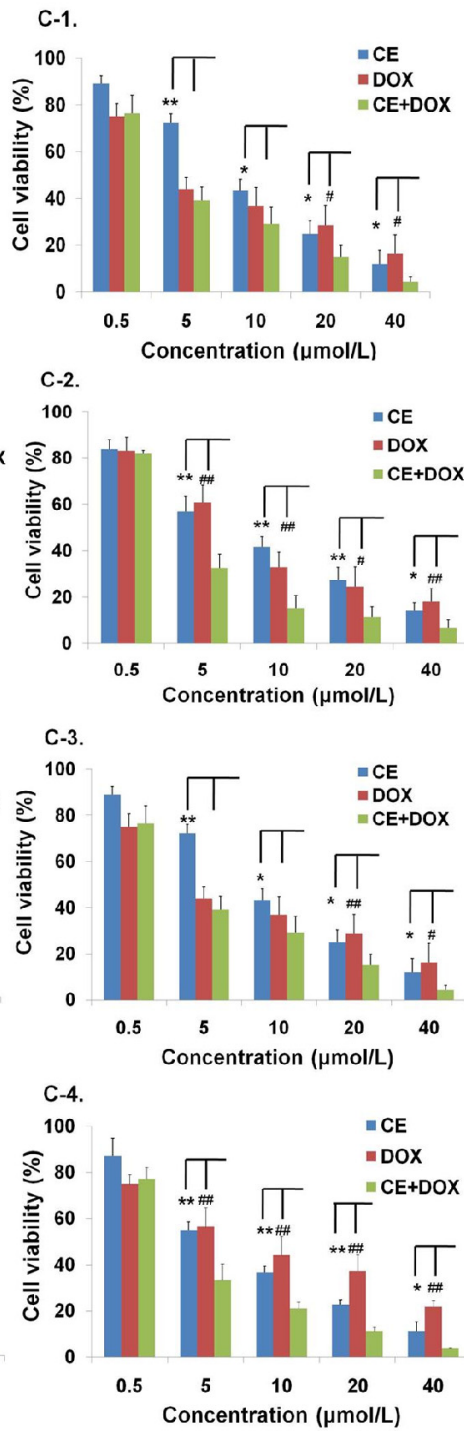
Figure 2. Combination index $(\mathrm{CI})$ values of $\mathrm{CE}+\mathrm{DTX}, \mathrm{CE}+\mathrm{PTX}$, and $\mathrm{CE}+\mathrm{DOX}$ at $50 \%$ growth inhibition point on B16, SKOV3, MCF-7, and HepG2 cells $(n=3)$.

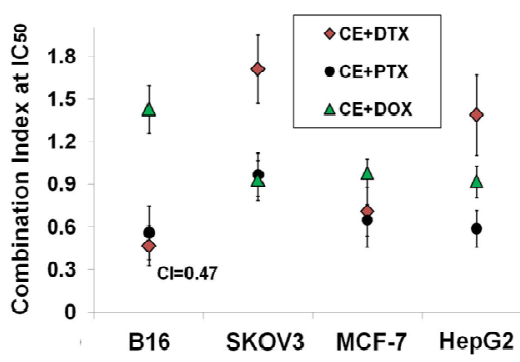

\subsection{Determination of the Optimal Dose Schedule of CE +DTX on B16 and MCF-7 Cells}

There is a need for optimizing the combination dose schedule of CE + DTX to realize its full therapeutic potential. It has previously been recognized that whether or not two agents interact synergistically or antagonistically is dependent on the ratio of the agents [27]. Moreover, the sequence of administration is particularly important since a given sequence might have an adverse result, such as antagonism instead of the required synergism [4]. Therefore, the experiments for screening of CE + DTX with optimal combination ratio and most suitable sequence of administration were carried out.

To determine the optimal combination ratio of CE and DTX, the anti-proliferation effects of CE + DTX with different combination ratio were tested by MTT assay and the corresponding CI values were calculated, respectively. As shown in Table 1, the CI values changed greatly (0.31-1.08 on B16 cells and $0.48-1.17$ on MCF-7 cells, respectively) along with the variation of the combination molar ratio, which proved the importance of combination ratio in combination therapy. When CE and DTX combined with a molar ratio of $0.5: 1$, the lowest CI values were obtained on B16 $(\mathrm{CI}=0.31)$ and MCF-7 cells $(\mathrm{CI}=0.48)$, respectively. Consequently, the combination molar ratio of CE and DTX was determined as $0.5: 1$. For the screening of sequence of administration, CE or DTX was added sequentially and the cell viability was measured. Unexpectedly, there was no significant difference on the anti-proliferation effects between different sequential treatments $(p>0.05)$. Therefore, the sequence of administration was considered to have no obvious effect on the synergistic effect of CE + DTX in the present study. Taken together, simultaneous administration of CE and DTX with a molar ratio of 0.5:1 was finally determined as the optimal dose schedule for later studies.

Table 1. Combination index (CI) values of CE + DTX with different combination molar ratio at $50 \%$ growth inhibition point on B16 and MCF-7 cells $(n=3)$.

\begin{tabular}{ccccccc}
\hline \multirow{2}{*}{ CE } & \multirow{2}{*}{ DTX } & \multicolumn{5}{c}{ Combination molar ratio } \\
\cline { 3 - 7 } & & $\mathbf{0 . 2 5}$ & $\mathbf{0 . 5}$ & $\mathbf{1}$ & $\mathbf{2}$ & $\mathbf{4}$ \\
\hline \multirow{2}{*}{ B16 } & CI at IC50 & $0.49 \pm 0.17$ & $0.31 \pm 0.13$ & $0.47 \pm 0.14$ & $0.95 \pm 0.26$ & $1.08 \pm 0.17$ \\
\cline { 2 - 7 } & Interpretation & synergism & strong synergism & synergism & additive effect & additive effect \\
\hline \multirow{3}{*}{ MCF-7 } & CI at IC50 & $0.62 \pm 0.13$ & $0.48 \pm 0.11$ & $0.79 \pm 0.25$ & $1.17 \pm 0.18$ & $1.03 \pm 0.19$ \\
\cline { 2 - 7 } & \multirow{2}{*}{ Interpretation } & $\begin{array}{c}\text { moderate } \\
\text { synergism }\end{array}$ & \multirow{2}{*}{ synergism } & $\begin{array}{c}\text { moderate } \\
\text { synergism }\end{array}$ & $\begin{array}{c}\text { moderate } \\
\text { antagonism }\end{array}$ & additive effect \\
\hline
\end{tabular}

Note: CI > 1.3: antagonism; CI 1.1-1.3: moderate antagonism; CI 0.9-1.1: additive effect; CI 0.8-0.9: slight synergism; CI 0.6-0.8: moderate synergism; CI 0.4-0.6: synergism; CI 0.2-0.4: strong synergism. 


\subsection{Induction of Apoptosis on B16 and MCF-7 Cells by CE + DTX}

To verify the synergistic effects of CE + DTX on B16 and MCF-7 cells, the apoptotic effects of CE + DTX were tested using Annexin V-FITC and PI apoptosis kit. The representative dot-plots illustrating apoptotic status were shown in Figure 3. In the case of B16 cells, the percentage of apoptotic cells (early apoptotic plus late apoptotic cells) treated with CE + DTX combination solution was $51.28 \% \pm 5.16 \%$, which was significantly higher in comparison with CE $(29.41 \% \pm 3.19 \%$, $p<0.01)$ or DTX $(17.64 \% \pm 4.32 \%, p<0.01)$, respectively. Furthermore, significantly higher proportion of late apoptosis caused by CE + DTX $(32.31 \% \pm 4.47 \%)$ was found compared with that of double-concentration DTX $(24.82 \% \pm 2.79 \%, p<0.01)$, as shown in Figure 3B. For MCF-7 cells, similar results were observed (Figure 3C,D). These results indicated the potential synergistic enhancement of cancer therapy using CE + DTX. Furthermore, lower concentration of CE + DTX was able to induce a significantly higher apoptosis in comparison with double-concentration of DTX and CE, which would provide some enlightenment on that CE + DTX combination treatment might provide a promising prospect on toxicity reduction of chemotherapy.

Figure 3. Induction of apoptosis caused by CE + DTX on B16 and MCF-7 cells $(n=3)$. Cells were treated with either CE $(10$ or $20 \mu \mathrm{M})$, DTX $(20$ or $40 \mu \mathrm{M})$, or CE + DTX (10 $\mu \mathrm{M}$ CE plus $20 \mu \mathrm{M}$ DTX) for $24 \mathrm{~h}$ incubation, while $0.3 \%$ DMSO-PBS served as control. (A,C) Representative dot-plots illustrating apoptotic status on B16 and MCF-7 cells; (B,D) Data summary and analysis of the proportion of B16 and MCF-7 cells in different periods was according to the results of flow cytometric analysis. $* * p<0.01$, statistically significant difference between CE and CE + DTX; ${ }^{\#} p<0.05,{ }^{\#} p<0.01$, statistically significant difference between DTX and CE + DTX.

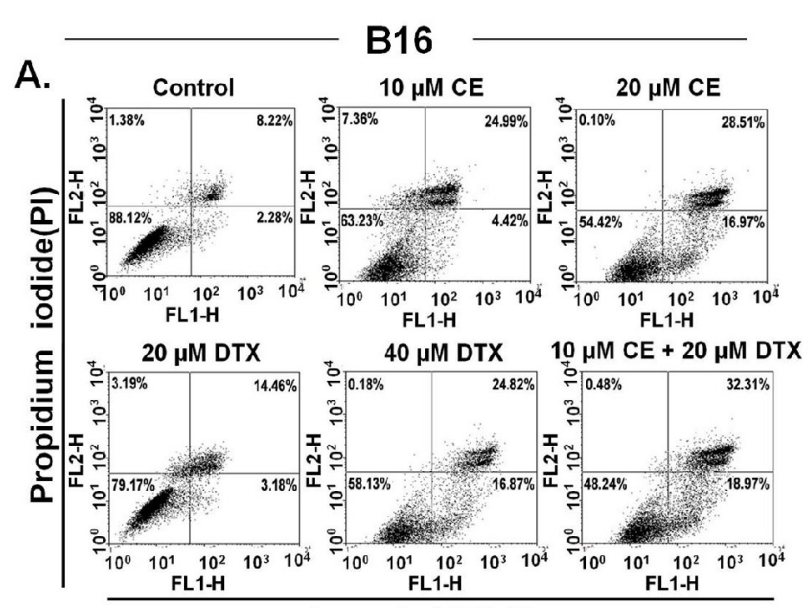

Annexin V-FITC

B.

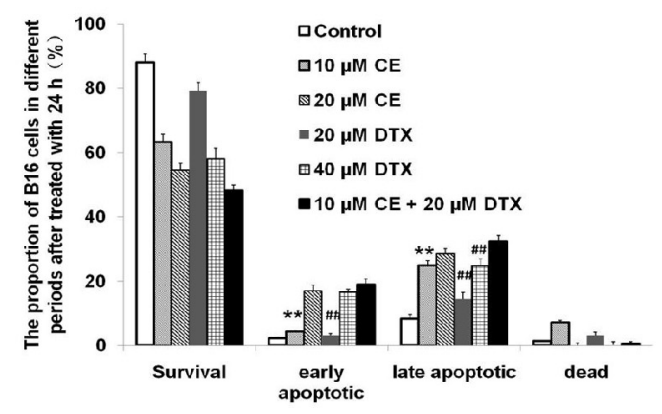

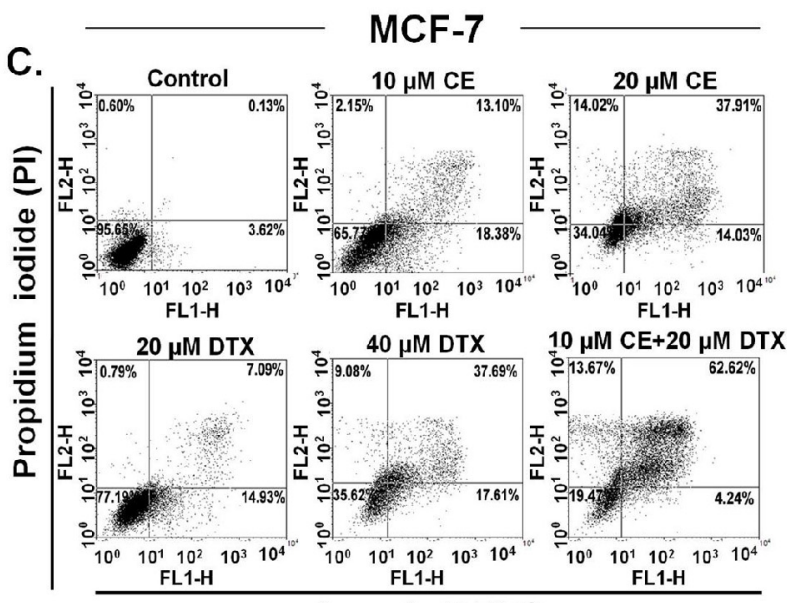

Annexin V-FITC

D.

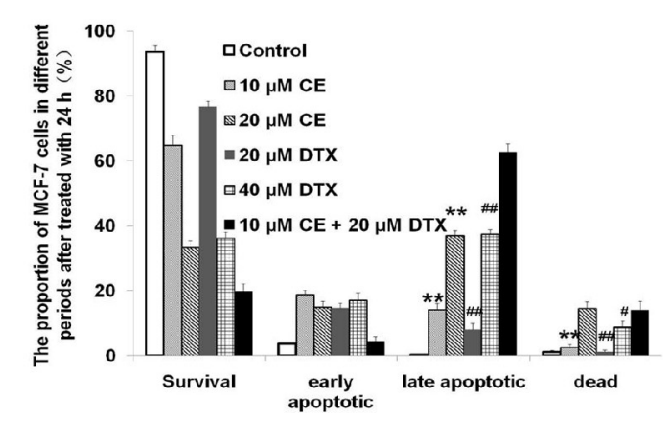




\subsection{Activation of Caspase-3 on B16 and MCF-7 Cells by CE +DTX}

Caspases-3 is one of the crucial mediators of apoptosis, being essential for certain processes associated with the dismantling of the cell and the formation of apoptotic bodies [28]. To confirm the probable pathways of synergistic apoptotic effect of CE + DTX, Caspase-3 activities of B16 and MCF-7 cells were evaluated by a Caspase-3 Activity Assay Kit. As shown in Figure 4, significantly higher Caspase-3 activity of B16 cells was observed upon cells treated with CE + DTX (10 $\mu \mathrm{M}$ CE plus $20 \mu \mathrm{M}$ DTX) comparing with that of cells treated with DTX $(20 \mu \mathrm{M})$, DTX $(40 \mu \mathrm{M})$, or CE $(10 \mu \mathrm{M})$ $(p<0.01)$, respectively. For MCF-7 cells, the Caspase-3 activity activated by CE + DTX was significantly higher than that of cells treated with DTX $(20 \mu \mathrm{M})$, DTX $(40 \mu \mathrm{M})$, or CE $(10 \mu \mathrm{M})$ $(p<0.01)$, respectively, and even higher than that of cells treated with $20 \mu \mathrm{M} \mathrm{CE}(p<0.05)$. These results were consistent with the study of apoptosis tests. Taking the aforementioned results together, it was reasonable to believe that the synergistic enhancement of apoptosis caused by CE + DTX was probably mediated by the significant activation of Caspase- 3 .

Figure 4. Significant enhancement of Caspase-3 activity caused by CE + DTX on B16 and MCF-7 cells $(n=3)$. Cells were treated with either CE $(10$ or $20 \mu \mathrm{M})$, DTX $(20$ or $40 \mu \mathrm{M})$, or CE + DTX (10 $\mu \mathrm{M}$ CE plus $20 \mu \mathrm{M}$ DTX) for $24 \mathrm{~h}$ incubation, while $0.3 \%$ DMSO-PBS served as control. The Caspase- 3 activity of cells with different treatments was evaluated by assessing the capacity to catalyze the cleavage of Caspase-3 substrate (Ac-DEVD-pNA) and release the pNA fluorochrome. (A) Caspase-3 activity of B16 cells; (B) Caspase-3 activity of MCF-7 cells. * $p<0.05, * * p<0.01$, statistically significant difference between CE and CE + DTX; ${ }^{\# \#} p<0.01$, statistically significant difference between DTX and $\mathrm{CE}+\mathrm{DTX}$.

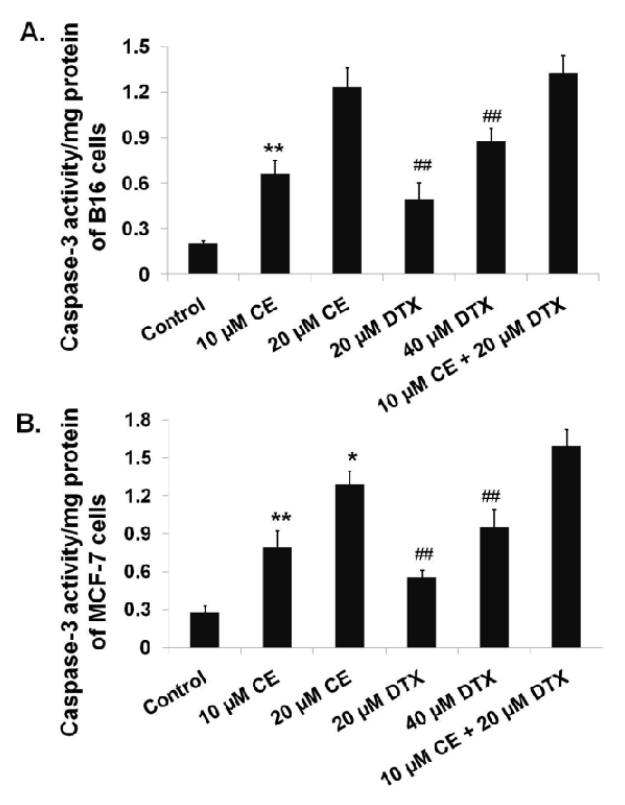

\subsection{Cell Cycle Effect of CE + DTX}

It has been intensively studied that cells have a higher frequency of arrest in G2/M phase by DTX [29], however, there is no published data to report the effect of CE on cell cycle progression. To 
better understand the mechanisms responsible for the synergistic anti-proliferative activity of CE + DTX, the cell cycle distribution of B16 and MCF-7 cells was evaluated by flow cytometric analysis. As shown in Figure 5, cells were arrested in G1 phase by CE while arrested in G2/M phase by DTX, both in dose-dependent manner. B16 cells were arrested in G2/M-phase (91.33\%) by CE + DTX, that was significantly higher in comparison with that of either agent alone $(p<0.01)$, with an accompanying decrease in the G1 phase or S phase. Moreover, the level of G2/M accumulation caused by CE + DTX was even significantly higher than that caused by double-concentration CE $(10 \mu \mathrm{M}, p<0.01)$ or DTX $(20 \mu \mathrm{M}, p<0.05)$. Considering the single agent $\mathrm{CE}$ has no effect on $\mathrm{G} 2 / \mathrm{M}$ arrest, it might be assumed that CE acted synergistically with DTX and consequently enhanced the therapeutic effect of DTX, which contributed to the synergistic arrest in G2/M phase. In accord with B16 cells, the redistribution of cell cycle caused by CE + DTX also occurred in MCF-7 cells, as is shown in Figure 5C,D. These results corroborated the synergy between CE and DTX, indicating that CE + DTX produced greater potential therapeutic effects might also via the significant enhancement of G2/M-phase accumulation.

Figure 5. Cell cycle effect of CE + DTX on B16 and MCF-7 cells $(n=3)$. Cells were treated with either CE $(5$ or $10 \mu \mathrm{M})$ or DTX $(10$ or $20 \mu \mathrm{M})$, or combination $(5 \mu \mathrm{M} \mathrm{CE}$ plus $10 \mu \mathrm{M}$ DTX) for $12 \mathrm{~h}$ incubation, while 0.3\% DMSO-PBS served as control. (A,C) Representative experiments on B16 and MCF-7 cells, respectively; (B,D) Data summary and analysis of the proportion of B16 cells and MCF-7 cells in different phase after treatment according to the results of flow cytometric analysis. $* * p<0.01$, statistically significant difference between CE and CE + DTX; ${ }^{\#} p<0.05,{ }^{\#} p<0.01$, statistically significant difference between DTX and CE + DTX.
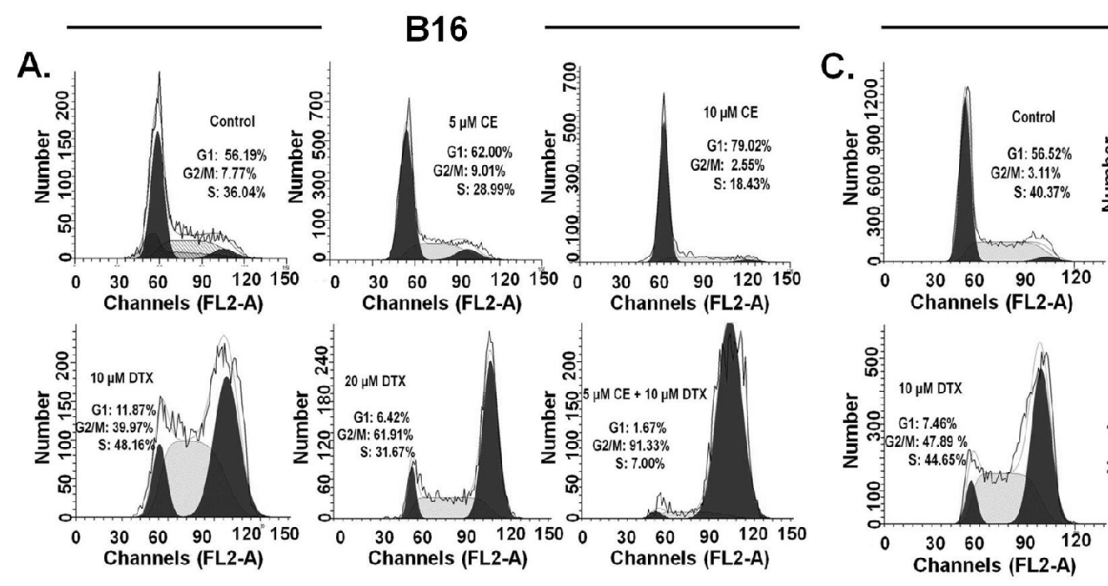

MCF-7
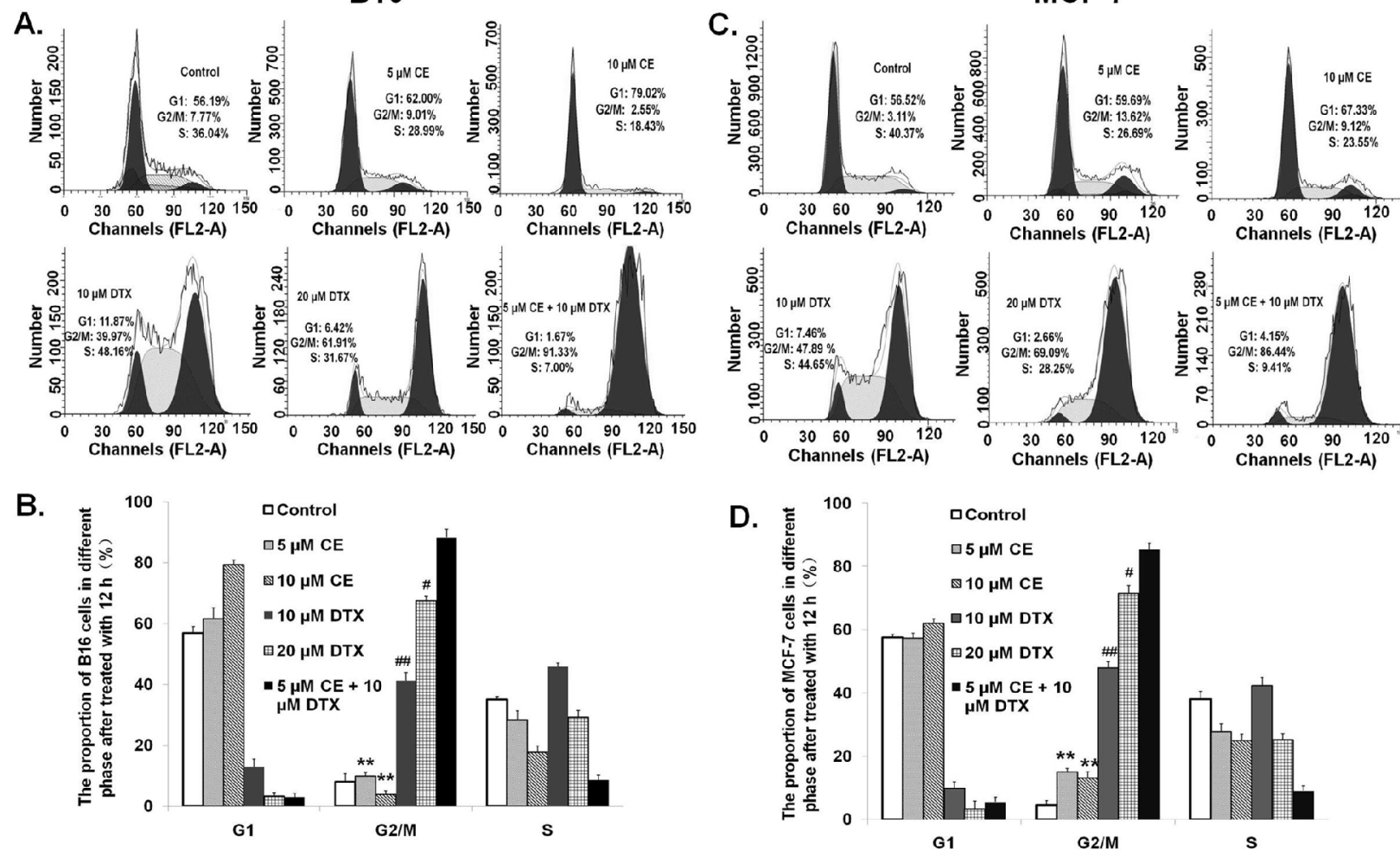


\subsection{Cytoskeleton Destruction Effect of CE + DTX}

Cytoskeleton is a dynamic structure essential for a wide variety of normal cellular processes, including the maintenance of cell shape and morphology, membrane dynamics, and signal transduction [30,31]. To explore whether CE and DTX have a synergistic effect on alteration of cytoskeleton, F-actin and $\beta$-tubulin of B16 and MCF-7 cells were specifically stained by FITC-phallacidin and Tubulin-Tracker Red, respectively, after treatment with CE + DTX (5 $\mu \mathrm{M}$ CE plus $10 \mu \mathrm{M}$ DTX) for $12 \mathrm{~h}$. The nuclei were stained by Hoechst 33342 in order to observe the cell morphology better.

As shown in Figure 6, CE + DTX not only made a strong destruction on microfilaments and microtubules in comparison with either agent alone, but also seriously damaged the cell morphology, demonstrating a synergistic effect on destruction of cytoskeleton. DTX specifically promoted the assembly of $\beta$-tubulin but not F-actin and obviously induced the polymerization of microtubule, resulting in the enhancement of red fluorescence intensity. This was consistent with the literature and well coincide with the results of the G2/M-phase arrest tests [29]. Meanwhile, cells treated with CE showed no significant alteration on microtubule, however, the stress fibers of F-actin disappeared obviously, predicating the destruction of the microfilaments cytoskeleton. For B16 cells, similar results were observed (Figure S1).

Figure 6. Cytoskeleton destruction effect of CE + DTX on MCF-7 cells $(n=3)$. The blue color indicated the location of nuclei, the green color indicated the location of F-actin and the red color represented the $\beta$-tubulin. The white arrows indicate the stress fibers of F-actin. Scale bar, $200 \mu \mathrm{m}$.

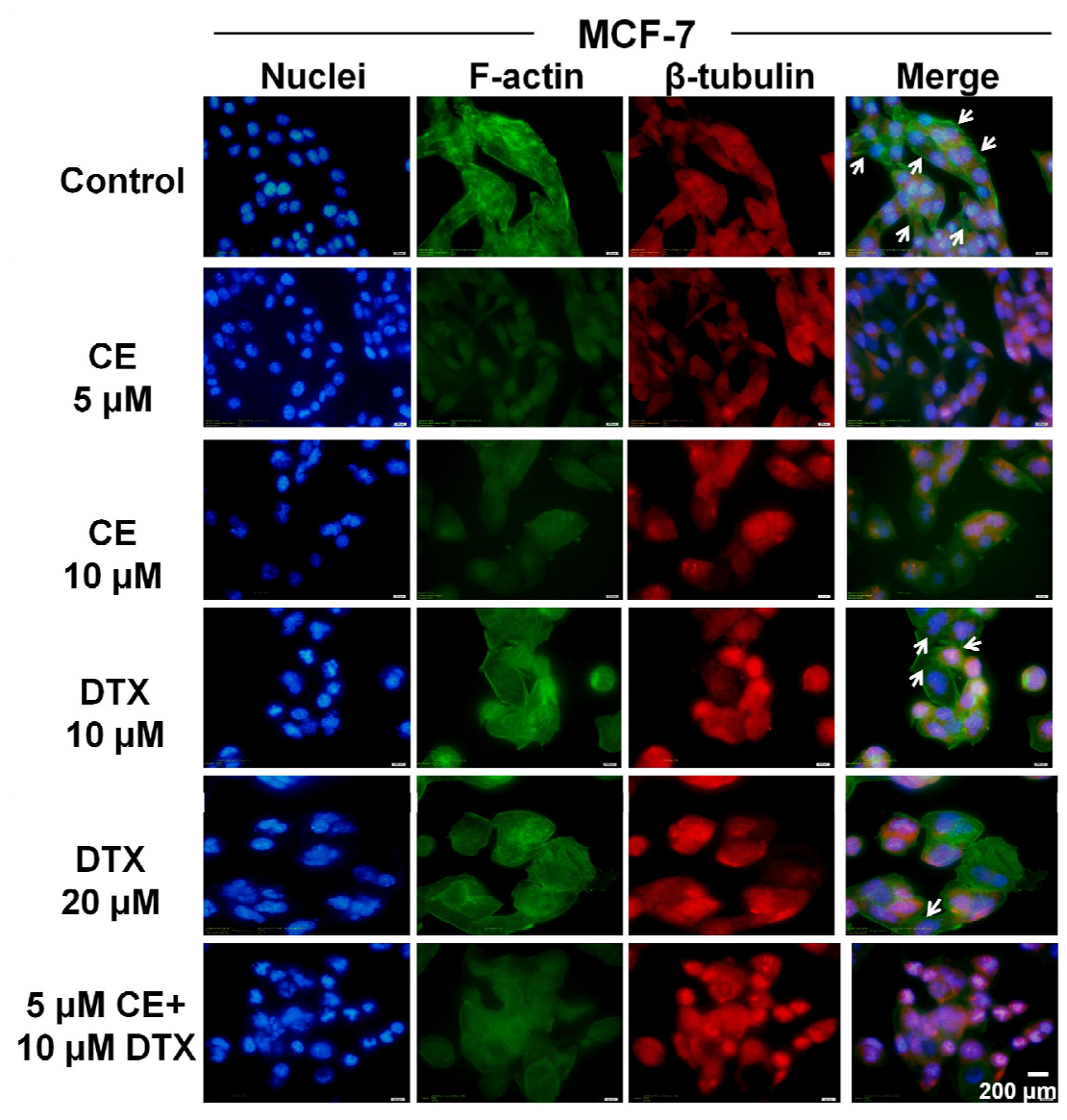


To obtain a clear relationship between CE and microfilaments cytoskeleton, cells were incubated with $5 \mu \mathrm{M} \mathrm{CE}$ for 12,24 , and $36 \mathrm{~h}$, respectively, the alterations of F-actin over time were observed. As shown in Figure 7, with prolongation of incubation time, the stress fibers of F-actin gradually disappeared and the polymerization of F-actin was significantly increased $(p<0.05)$. The flow cytometric results showed that B16 cells incubated with $5 \mu \mathrm{M} \mathrm{CE}$ for 12,24 , and $36 \mathrm{~h}$ showed $16.58 \% \pm 5.58 \%, 51.21 \% \pm 6.34 \%$, and $69.52 \% \pm 3.69 \%$ fluorescence positivity, respectively, while MCF-7 cells showed $38.40 \% \pm 4.78 \%, 54.92 \% \pm 5.70 \%$, and $78.62 \% \pm 4.45 \%$ fluorescence positivity, respectively. These results quantitatively proved the polymerization of F-actin and finally resulted in strong destruction of actin cytoskeleton. In addition, the destruction of actin cytoskeleton was accompanied by apoptosis as obvious fragmentation of nuclei and formation of apoptotic bodies were found after incubation with CE (Figure 7). Thus, it would be considered that CE could target and disrupt the actin cytoskeleton, resulting in the induction of apoptosis of cells subsequently. In conclusion, CE and DTX acted complementarily to destruct the cytoskeleton structure on B16 and MCF-7 cells, which could also lead to the significant enhancement of antitumor effect of CE + DTX.

Figure 7. Alterations of microfilaments cytoskeleton caused by $\mathrm{CE}$ on B16 and MCF-7 cells $(n=3)$. The blue color indicated the location of nuclei and the green color indicated the location of F-actin. The white arrows indicate the formation of apoptosis body or stress fibers of F-actin. Scale bar, $200 \mu \mathrm{m}$.

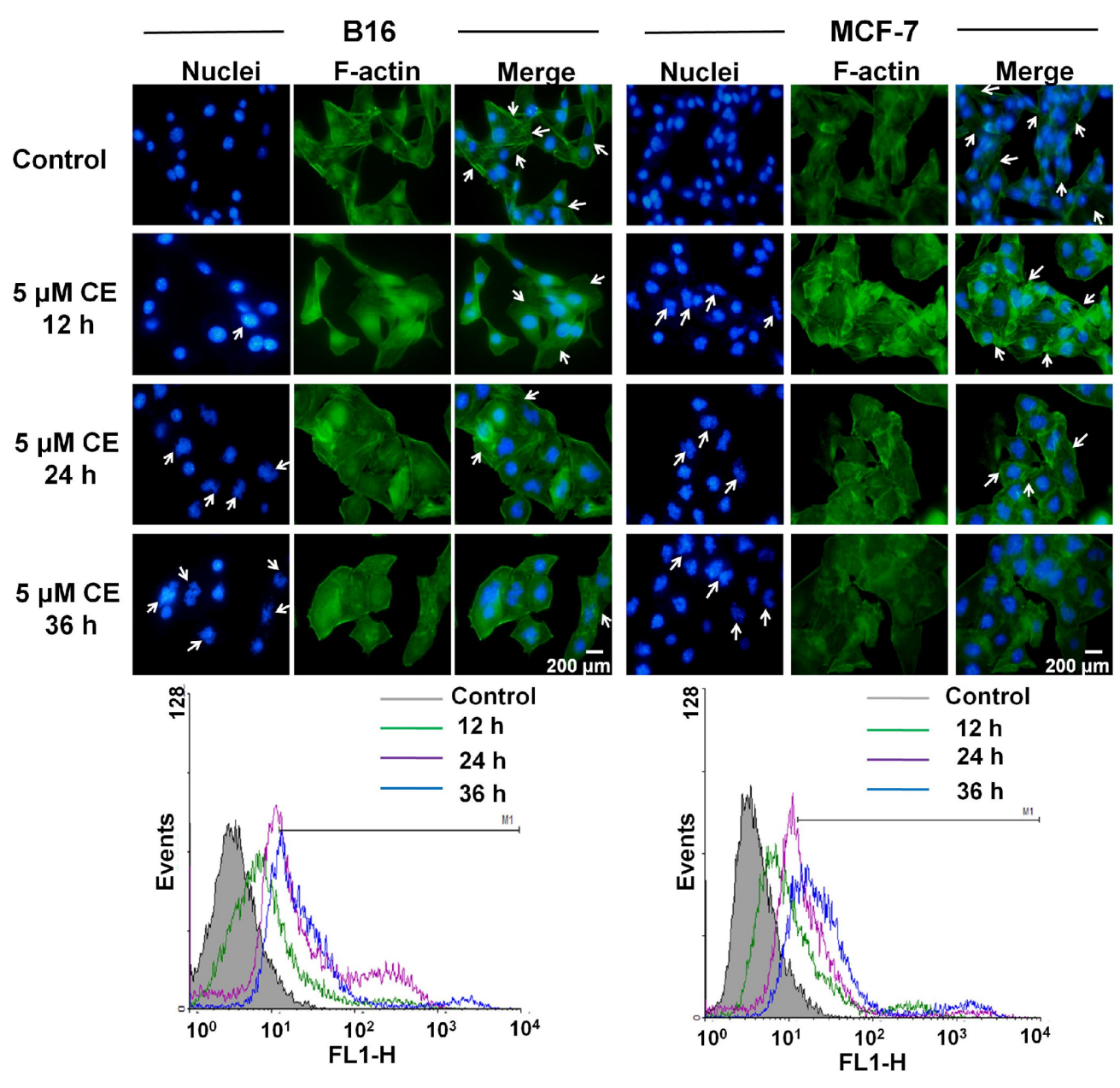




\subsection{In Vivo Anti-Tumor Effect of CE + DTX}

Given that the synergistic effect of CE + DTX in vitro, it was essential to determine whether CE combined with DTX could enhance the antitumor activity in vivo. Therefore, the anti-tumor activity of CE + DTX (CE: $2.5 \mathrm{mg} / \mathrm{kg}$, DTX: $10 \mathrm{mg} / \mathrm{kg}$ ) was evaluated using B16 tumor-bearing mice, $2.5 / 5 \mathrm{mg} / \mathrm{kg} \mathrm{CE}, 10 / 20 \mathrm{mg} / \mathrm{kg}$ DTX, and N.S were served as controls. The variation on tumor volume and body weight with different administration were monitored and recorded respectively, as shown in Figure 8 .

Figure 8. Antitumor effects of CE + DTX on B16 tumor-bearing mice after intravenous administration $(n=5) .2 .5 / 5 \mathrm{mg} / \mathrm{kg}$ CE, $10 / 20 \mathrm{mg} / \mathrm{kg}$ DTX and N.S were served as controls. (A) Tumor volume; (B) Tumor weight; (C) Body weight. ** $p<0.01$, statistically significant difference between CE and CE + DTX; ${ }^{\#} p<0.05,{ }^{\#} p<0.01$, statistically significant difference between DTX and CE + DTX.

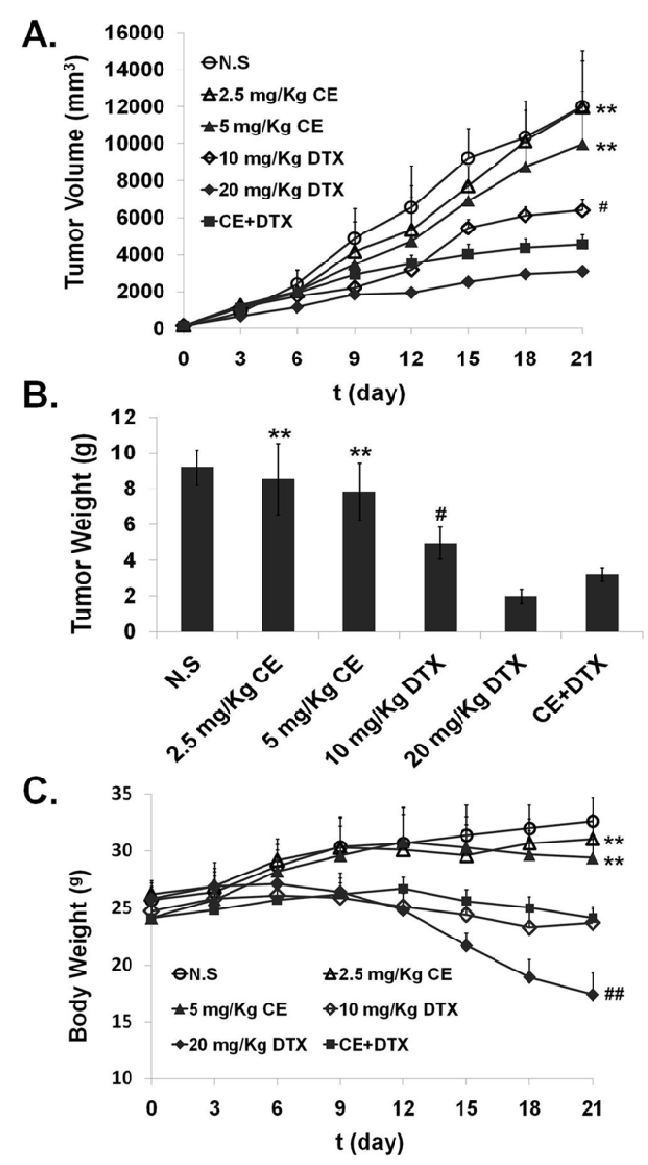

Tumor volume is an important indicator for evaluating antitumor efficacy of the different therapy regimens [32]. As shown in Figure 8A, the antitumor efficacy of CE + DTX was significantly higher than that of single-dose of CE $(2.5 \mathrm{mg} / \mathrm{kg}, p<0.01)$ and DTX $(10 \mathrm{mg} / \mathrm{kg}, p<0.05)$, and even significantly higher than that of double dose of CE $(5 \mathrm{mg} / \mathrm{kg}, p<0.01)$, indicating the synergistic antitumor efficacy in vivo. To quantitatively evaluate the tumor regression effect of CE + DTX, the excised tumor of sacrificed mice were weighed. In accordance with the results of tumor volume, the 
tumor weight of mice after treatment with CE + DTX was $3.024 \pm 0.36 \mathrm{~g}$, which was significantly smaller than that of CE $(2.5 / 5 \mathrm{mg} / \mathrm{kg}, p<0.01)$ and DTX $(10 \mathrm{mg} / \mathrm{kg}, p<0.05)$ (Figure 8B), respectively.

On the other hand, severe systematic toxicity accompanying the high dose anti-cancer drugs is also a limiting factor for chemotherapy. The body weights of mice were monitored as an index of systemic toxicity [33] and the body weight variations of mice was shown in Figure 8C. During the experiment period, the weight loss induced by CE + DTX was significantly lower than that induced by DTX $(20 \mathrm{mg} / \mathrm{kg}, p<0.01)$, displaying a significantly lower systematic toxicity. The body weight of mice treated with CE + DTX was even higher than that of mice treated with $10 \mathrm{mg} / \mathrm{kg} \mathrm{DTX}$, which could verify our abovementioned opinion and further prove the safety of CE + DTX combination treatment. Although the body weight of mice treated with CE + DTX was lower comparing with that of N.S and $2.5 / 5 \mathrm{mg} / \mathrm{kg} \mathrm{CE}$, this phenomenon might be caused by the significant increase of tumor weight of the mice treated with N.S and $2.5 / 5 \mathrm{mg} / \mathrm{kg}$ CE (Figure 8A,B). Overall, these results indicated that CE combined with DTX could generate a synergistic antitumor efficacy in vivo and reduce the systematic toxicity in murine malignant melanoma model.

\section{Discussion}

Combination therapy plays a more and more important role in in the field of anti-cancer therapy and CE-based combination therapy as a novel therapeutic strategy has attracted great attention. To evaluate whether exogenous CE could in synergy with different anti-cancer drugs on various cancer cells, a comprehensive exploration of all possible combinations is ideal but cost-prohibitive and time-prohibitive. Based on these considerations, three traditionally and widely used anti-cancer drugs (DTX, PTX, and DOX) were selected as model drugs, correspondingly, the sensitive cell lines B16, MCF-7, SKOV3, and HepG2 were selected as model cells.

For preliminary screening, the combination molar ratio was fixed at 1:1 [34], therefore, the cytotoxicity of CE combination (CE + DTX, CE + PTX, or CE + DOX) at molar ratio 1:1 was evaluated at various concentrations by MTT assay on B16, MCF-7, SKOV3, and HepG2 cells, respectively. It was worth mentioning that, DTX and PTX should be expected to impose a large inhibitory growth response on these chosen cancer cells, however, the observed IC50 value for single agent DTX or PTX was large and higher than that of previous findings [35,36]. To verify these results, Taxol $^{\circledR}$ (Bristol-Myers Squibb, New York, NY, USA) and Duopafei ${ }^{\circledR}$ were set as controls, finding that the cytotoxicity of Duopafei ${ }^{\circledR}$ (Qilu Pharmaceutical Co., Ltd., Ji'nan, China) and Taxol ${ }^{\circledR}$ to cells were high, as the IC50 values were much lower (Duopafei ${ }^{\circledR}: 2.31 \mu \mathrm{M}$ on MCF-7 cells and Taxol ${ }^{\circledR}: 1.59 \mu \mathrm{M}$ on $\mathrm{B} 16$ cells). It was indicated that the high cytotoxicity of Duopafei ${ }^{\circledR}$ and Taxol ${ }^{\circledR}$ were probably caused by Tween ${ }^{\circledR}$-80-ethanol (Sinopharm Co., Ltd., Shanghai, China) and Cremophore EL ${ }^{\circledR}$-ethanol (Sinopharm Co., Ltd., Shanghai, China), respectively.

CI assay, a commonly used evaluation methods to investigate whether there exists synergistic effects was developed from Chou [27]. In our study, simultaneous administration of CE and DTX at molar ratio of 0.5:1 showed highest synergistic effects on B16 and MCF-7 cells. Despite of some negative results, it is inappropriate to make an absolute or assertive conclusion that $\mathrm{CE}+\mathrm{DTX}$ should be inhibited on SKOV3 cells or HepG2 cells (CI > 1.3, Figure 2). The exceptional results probably caused by the heterogeneity of different cancer cells and the diverse anti-cancer mechanisms of 
different drugs. Moreover, the irrational combination ratio of the combined agents or the inappropriate sequence of administration could also contribute to the negative results, which was also proved in Table 1. The CI test reminded that rational and effective designed strategies are important in combination therapy.

$\mathrm{CE}$ is one of the important intracellular signaling molecules, playing an important role in apoptosis [20], while DTX has been intensively studied to make cells have a higher frequency in G2/M arrest [29]. Based on these considerations, the apoptosis and cell cycle study was carried out. It was showed that, DTX could synergistically promote the apoptosis effect of CE, resulting in the significantly higher proportion of apoptosis cells (Figure 3). On the other hand, CE could act synergistically with DTX and consequently enhance the therapeutic effect of DTX, which contributed to the synergistic arrest in G2/M phase (Figure 5). Both the apoptosis and cell cycle study corroborated the synergy between CE and DTX.

As mentioned above, cytoskeleton is a dynamic structure essential for a wide variety of normal cellular processes, including the maintenance of cell shape and morphology, membrane dynamics and signal transduction [30,31]. Cytoskeleton could be organized into microtubules, microfilaments and intermediate filaments. Among them, microtubules have been extensively and clearly studied as targets of taxanes, such as Taxol and docetaxel, which have been used successfully clinically in treating various malignant diseases [37,38]. Microfilament actin is ubiquitous protein present in all eukaryotic cells and the disruption of F-actin has been found in malignant transformed cells [39]. Actin polymerization and remodeling play a critical role in the morphologic and phenotypic events in cancer cells [40]. Thus, it is reasonable to assume that microfilament actin, such as microtubules, could be a potential target for anti-cancer drug development [39,41].

In the present study we found that $\mathrm{CE}$ could target the microfilament actin, leading to the polymerization and destruction of actin cytoskeleton. As a result, Caspase-3 was activated [28] and subsequently induced apoptosis. The close relationship between apoptosis and Caspase- 3 has also been proved in Figure 3. Meanwhile, DTX could target and disrupt the microtubules cytoskeleton, leading to a high proportion of cancer cells in G2/M-phase arrest. Moreover, CE plus DTX could cause a synergistic destruction of cytoskeleton, which resulted in a significantly higher apoptosis and a significantly higher arrest in G2/M arrest comparing with either agent alone $(p<0.01)$. Therefore, it is reasonable to deduce that the anti-tumor mechanisms of CE and DTX are probably complementary, which may contribute to a synergistic therapeutic effect of CE + DTX. The in vivo antitumor study also verified the synergy between CE and DTX, as CE + DTX could achieve a significantly higher antitumor efficacy than either agent alone (DTX, $p<0.05$; CE, $p<0.01$, Figure 8).

\section{Experimental Section}

\subsection{Materials}

Ceramide (CE) was obtained from Avanti Polar Lipids, Inc., Alabaster, AL, USA. Paclitaxel (PTX) and docetaxel (DTX) were provided by Chenxin Pharmaceutical Co., Ltd., Jining, China. Doxorubicin $\mathrm{HCl}$ (DOX) was purchased from Dalian Meilun Biology Technology Co., Ltd., (Dalian, China). 3-(4,5-Dimethylthiazol-2-yl)-2,5-diphenyltetrazoliumbromide (MTT) was purchased from Solarbio 
(Shanghai, China). Annexin V-FITC and propidium iodide (PI) apoptosis kit was provided by Bestbio (Shanghai, China). Caspase-3 Activity Assay Kit and Tubulin-Tracker Red were obtained from Beyotime (Shanghai, China). RNase A and PI were provided by TransGen Biotech Co., Ltd., (Beijing, China). FITC-Phallacidin and Hoechst 33342 were purchased from Invitrogen by Life Technologies (Carlsbad, CA, USA).

All the other chemicals and reagents used were of analytical purity grade or higher, obtained commercially.

\subsection{Cell Lines and Cell Culture}

Murine melanoma cell line (B16) and human breast carcinoma cell line (MCF-7) were purchased from the Chinese Academy of Sciences (Shanghai, China). Human ovarian carcinoma cell line (SKOV3) and human hepatocellular carcinoma cell line (HepG2) were kindly provided by Institute of Immunopharmacology and Immunotherapy of Shandong University (Ji'nan, China). HepG2 cell line was cultured in $25 \mathrm{~cm}^{2}$ culture flask in DMEM media, while B16, MCF-7 and SKOV3 cell lines were cultured in RPMI-1640 media at $37{ }^{\circ} \mathrm{C}$ under $5 \% \mathrm{CO}_{2}$. All the media were supplemented with $10 \%(v / v)$ fetal bovine serum from Sijiqing Co., Ltd., (Hangzhou, China), streptomycin at $100 \mu \mathrm{g} / \mathrm{mL}$ and penicillin at $100 \mathrm{U} / \mathrm{mL}$.

\subsection{Animals}

The female Kunming mice (weight: 18-22 g, age: 6-8 weeks) were supplied by the Medical Animal Test Center of Shandong University (Ji'nan, China). The animals were acclimatized for at least $48 \mathrm{~h}$ before experimentation, fed with a standard diet and allowed water ad libitum. All experiments were carried out in compliance with the Animal Management Rules of the Ministry of Health of the People's Republic of China (document number 55, 2001) and the Animal Experiment Ethics Review of Shandong University.

\subsection{Anti-Proliferation Test in Vitro}

To investigate the anti-proliferation effects of CE-based combination treatment, an MTT assay was performed on B16, SKOV3, MCF-7, and HepG2 cells, respectively, following the manufacturer's instructions. Briefly, cells in the exponential growth phase were counted and added into the 96-multiwell plate. Cells were allowed to adhere overnight at $37{ }^{\circ} \mathrm{C}$ and $5 \% \mathrm{CO}_{2}$ before drug treatments. To prepare the stock solution, CE, PTX, and DTX were dissolved in dimethyl sulfoxide (DMSO) while DOX was dissolved in $\mathrm{pH}$ 7.4, 0.01 M phosphate-buffered saline (PBS). The stock solutions (CE solution, DTX solution, PTX solution or DOX solution) were serially diluted with serum supplemented media, making sure the final concentration of the drug was $0.5,5,10,20$, and $40 \mu \mathrm{M}$, respectively. To test the synergistic anti-proliferation effect of CE-based combination (CE plus DTX, CE plus PTX, or CE plus DOX), the corresponding combination solutions (CE + DTX, CE + PTX, and CE + DOX) were prepared proportionally at 1:1 molar ratio, respectively, making sure the final concentration of each agent was consistent with the above-mentioned concentration. Cells grown in the media containing an equivalent amount of DMSO without any drug served as control. The maximal concentration of 
DMSO in all the experimental wells was lower than $0.3 \%(v / v)$ [42]. After $48 \mathrm{~h}$ incubation, the cell viability was determined by absorbance measurements at $570 \mathrm{~nm}$ and a reference wavelength of $630 \mathrm{~nm}$, measured by a microplate reader (FL600, Bio-Tek Inc., Winooski, VT, USA).

To optimize the dosing schedule, the synergistic effects of CE + DTX with different combination ratio and different sequence of administration were subsequently investigated (DTX was selected based on the results of the primary anti-proliferation tests mentioned above). To screen the optimal combination ratio, a series of concentration gradients of CE + DTX combination solutions were prepared proportionally at 0.25:1 4:1 molar ratio, and the anti-proliferation effects were studied by MTT method mentioned above. Based on the obtained optimal combination ratio, a series of concentration gradients of CE solution and DTX solution were prepared separately and administered in a chronological order $(-4,-2,0,2,4 \mathrm{~h})$, to determine the optimal sequence of administration. All the other operations were consistent with the above-mentioned methods.

\subsection{Calculation of Combination Index (CI)}

The specific interaction between CE and DTX, PTX, or DOX on various cancer cell lines was evaluated by the combination index (CI) assay [24-26], respectively. The CI values were calculated based on the results of anti-proliferation tests and $C I=D_{1} / D_{f 1}+D_{2} / D_{f 2}+D_{1} D_{2} / D_{f 1} D_{f 2}$. Where $D_{f 1}$ is the concentration of Drug-1 required to produce x percent effect alone and $\mathrm{D}_{1}$ is the concentration of Drug-1 required to produce the same x percent effect in combination with Drug-2; Similarly, $\mathrm{D}_{\mathrm{f} 2}$ is the concentration of Drug-2 required to produce $x$ percent effect alone and $\mathrm{D}_{2}$ is the dose of Drug-2 required to produce the same $\mathrm{x}$ percent effect in combination with Drug-1. Consequently, $\mathrm{CI}>1.3$ : antagonism; CI 1.1-1.3: moderate antagonism; CI 0.9-1.1: additive effect; CI 0.8-0.9: slight synergism; CI 0.6-0.8: moderate synergism; CI 0.4-0.6: synergism; CI 0.2-0.4: strong synergism. In the present study, CI values at $50 \%$ growth inhibition effect were tested.

\subsection{Induction of Apoptosis on B16 and MCF-7 Cells}

To verify the synergistic effect of CE combination, the induction of apoptosis caused by CE + DTX on B16 and MCF-7 cells were carried out. Apoptosis detection was performed using the Annexin V-FITC and PI apoptosis kit (Bestbio, Shanghai, China). B16 and MCF-7 cells were plated at a density of $2 \times 10^{5}$ cells/well into 12-well plates and incubated overnight. Apoptosis was induced by treating cells with CE + DTX combination solution (final concentrations of CE and DTX were 10 and $20 \mu \mathrm{M}$, respectively). Cells treated with CE solution $(10$ or $20 \mu \mathrm{M})$ and DTX solution $(20$ or $40 \mu \mathrm{M})$ were set at the same time to make a valid comparison against CE + DTX. Cells grown in media containing an equivalent amount of DMSO without any drug were served as control. After $24 \mathrm{~h}$ of incubation, the cells with different treatments were harvested and the final samples were measured on a FACS Calibur flow cytometry (BD Biosciences, Franklin Lakes, NJ, USA).

\subsection{Evaluation of Caspase-3 Activity}

In order to investigate whether CE + DTX would significantly activate Caspase- 3 in comparison with CE or DTX, the Caspase-3 activity after different treatments on B16 and MCF-7 cells were 
evaluated by Caspase-3 Activity Assay Kit. Briefly, Caspase-3 was activated by treating cells with $\mathrm{CE}+\mathrm{DTX}$ combination solution (final concentrations of CE and DTX were 10 and $20 \mu \mathrm{M}$, respectively). Cells treated with CE solution $(10$ or $20 \mu \mathrm{M})$ and DTX solution $(20$ or $40 \mu \mathrm{M})$ were set as controls. Cells grown in media containing an equivalent amount of DMSO without any drug were served as blank control. After $24 \mathrm{~h}$ incubation, the cells with different treatments were harvested and resuspended with $1 \times$ lysis buffer in the assay kit for $15 \mathrm{~min}$ at $0{ }^{\circ} \mathrm{C}$, and then centrifuged at $20,000 \times \mathrm{g}$ for $15 \mathrm{~min}$ to collect the supernatant containing cell extracts. To initiate the enzymatic reaction, the fresh cell extracts with different treatments were transferred into the well of a 96-well plate, respectively, followed by the addition of assay buffer and Caspase-3 substrate (Ac-DEVD-pNA). The absorbance was measured at $405 \mathrm{~nm}$ by a microplate reader (FL600, Bio-Tek Inc., Winooski, VT, USA), making sure the plate was maintained in dark at $37{ }^{\circ} \mathrm{C}$ during the measurements. In order to quantify the Caspase- 3 activity, the protein content of each drug treatment was evaluated by Bradford protein assay (Beyotime, Shanghai, China), following the manufacturer's assay instructions.

\subsection{Cell Cycle Analysis of B16 and MCF-7 Cells}

To study the effects of CE combination on cell cycle distribution, cell cycle analysis was assessed using flow cytometry. B16 and MCF-7 cells were exposed to CE + DTX combination solution (final concentration of CE and DTX were 5 and $10 \mu \mathrm{M}$, respectively) at $37{ }^{\circ} \mathrm{C}$ under $5 \% \mathrm{CO}_{2}$, while cells treated with CE solution ( 5 or $10 \mu \mathrm{M})$ and DTX solution (10 or $20 \mu \mathrm{M})$ were set as controls. Cells grown in media containing an equivalent amount of DMSO without any drug served as blank control. After $12 \mathrm{~h}$ incubation, the cells were harvested and fixed overnight in cold $75 \%$ ethanol at $4{ }^{\circ} \mathrm{C}$. After that, cells were washed again with pre-cold PBS and incubated with $100 \mu \mathrm{L}$ RNase $(100 \mu \mathrm{g} / \mathrm{mL})$ at $37{ }^{\circ} \mathrm{C}$ for $1 \mathrm{~h}$. Subsequently, cells were stained with $100 \mu \mathrm{L}$ PI $(100 \mu \mathrm{g} / \mathrm{mL})$ for $15 \mathrm{~min}$ at $4{ }^{\circ} \mathrm{C}$ in dark, and subjected to FACS Calibur flow cytometry (BD Biosciences, Franklin Lakes, NJ, USA), to determine the percentage of cells in specific phase of the cell cycle (G1, S, and G2/M).

\subsection{Cytoskeleton Destruction and Actin-Polymerization Study}

To identify the destruction of cytoskeleton caused by CE + DTX, the cytoskeleton was stained and observed. B16 and MCF-7 cells were cultured in $35 \mathrm{~mm}$ glass bottom dishes in complete medium for $24 \mathrm{~h}$ attachment, then were exposed to CE + DTX combination solution (final concentration of CE and DTX were 5 and $10 \mu \mathrm{M}$, respectively) for $12 \mathrm{~h}$ at $37{ }^{\circ} \mathrm{C}$ under $5 \% \mathrm{CO}_{2}$. Cells treated with CE solution (5 or $10 \mu \mathrm{M}$ ) and DTX solution $(10$ or $20 \mu \mathrm{M}$ ) were set as controls. Cells grown in media containing an equivalent amount of DMSO without any drug served as blank control. After being fixed with 4\% paraformaldehyde in PBS, the cells were permeabilized with $0.1 \%$ Triton X-100 and subsequently treated with $3 \%$ bovine serum albumin (BSA)-PBS solution. Actin filament (F-actin) was stained with FITC-phallacidin $(4 \mu \mathrm{g} / \mathrm{mL})$ and $\beta$-tubulin was stained with Tubulin-Tracker Red $(3 \mu \mathrm{g} / \mathrm{mL})$, respectively, for $1 \mathrm{~h}$ at $37{ }^{\circ} \mathrm{C}$. Then Hoechst 33342 staining was performed to stain the nucleus. Finally, the glass bottom dishes were examined and photographed under a fluorescence microscope (BX40, Olympus, Tokyo, Japan).

To further investigate the polymerization of actin caused by CE, the flow cytometry assay was employed. B16 and MCF-7 cells were treated with fresh culture media containing CE at concentration 
of $5 \mu \mathrm{M}$ for 12,24 , and $36 \mathrm{~h}$, respectively. Actin filament (F-actin) was stained with FITC-phallacidin (4 $\mu \mathrm{g} / \mathrm{mL})$. After that, cells were trypsinized and harvested. Then, the samples were measured by FACS Calibur flow cytometry (BD Biosciences, Franklin Lakes, NJ, USA).

\subsection{In Vivo Antitumor Efficacy Evaluation}

In order to verify the in vivo synergistic effects of $\mathrm{CE}$ combination, the in vivo antitumor efficacy evaluation was experimented. The antitumor effect of CE + DTX was evaluated in Kunming mice $(18-22 \mathrm{~g})$ inoculated with B16 melanoma cells $\left(3 \times 10^{5}\right)$ by subcutaneously injection at the right axillary space. Treatments were started after 10-12 days of the implantation. The mice with tumor volume of $\sim 100 \mathrm{~mm}^{3}$ were selected and this day was designated as "Day 0". The mice were randomly assigned to 6 treatment groups: (1) $2.5 \mathrm{mg} / \mathrm{kg} \mathrm{CE}$; (2) $5 \mathrm{mg} / \mathrm{kg} \mathrm{CE}$; (3) $10 \mathrm{mg} / \mathrm{kg}$ DTX [36]; (4) $20 \mathrm{mg} / \mathrm{kg}$ DTX [43,44]; (5) CE + DTX (DTX: dosage of $10 \mathrm{mg} / \mathrm{kg}$, CE: dosage of $2.5 \mathrm{mg} / \mathrm{kg}$, final combination molar ratio of CE and DTX was 0.5:1); (6) normal saline (N.S). CE-solution was obtained by diluting DMSO stock solution with physiological saline while DTX-solution and CE + DTX-solution were obtained by diluting the Tween ${ }^{\circledR}$-80-ethanol stock solution (Sinopharm Co., Ltd., Shanghai, China) with physiological saline. The mice were administered intravenously with the above-mentioned formulations once every three days for 21 days $[43,44]$.

All mice were labeled, and the tumors were measured every three days with calipers during the period of study. The tumor volume was calculated by the formula:

$$
V=\left(W^{2} \times L\right) / 2
$$

where $W$ is the tumor measurement at the widest point and $L$ is the tumor dimension at the longest point. Each animal was weighed at the time of administration, so that the dosage could be adjusted to achieve the required dose $(\mathrm{mg} / \mathrm{kg})$ reported. After 21 days, the animals were sacrificed and the tumor mass was harvest and weighed.

\subsection{Statistical Analysis}

All studies were repeated a minimum of three times and measured at least in triplicate. Results were reported as means \pm standard deviation SD. Statistical significance was analyzed using the Student's $t$-test. Differences between experimental groups were considered significant when the $p$-value was less than $0.05(p<0.05)$.

\section{Conclusions}

This study made a comparatively comprehensive exploration on the potential application of CE in combination with anti-cancer drugs, making up for the deficiency of the previous research in the field of CE-based combination therapy. Meanwhile, the synergy mechanisms of CE + DTX were firstly elucidated. All these results in our study might provide a theoretical basis for CE combination and established a proof-of-concept that a rational combination of CE with DTX could generate synergistic effects on cancer treatments, which is highly promising for preclinical and clinical investigation to enhance therapeutic efficacy. 


\section{Acknowledgments}

This work was supported by the National Natural Science Foundation (No. 81072585).

\section{Conflicts of Interest}

The authors declare no conflict of interest.

\section{References}

1. Jemal, A.; Siegel, R.; Ward, E.; Hao, Y.; Xu, J.; Murray, T.; Thun, M.J. Cancer statistics, 2008. CA Cancer J. Clin. 2008, 58, 71-96.

2. Parkin, D.M.; Bray, F.; Ferlay, J.; Pisani, P. Global cancer statistics, 2002. CA Cancer. J. Clin. 2005, 55, 74-108.

3. Schally, A.V.; Engel, J.B.; Emons, G.; Block, N.L.; Pinski, J. Use of analogs of peptide hormones conjugated to cytotoxic radicals for chemotherapy targeted to receptors on tumors. Curr. Drug Deliv. 2011, $8,11-25$.

4. DeVita, V.T.; Chu, E. A history of cancer chemotherapy. Cancer Res. 2008, 68, 8643-8653.

5. Bevis, K.S.; Erwin, J.L.; Barnes, M.N.; Straughn, J.M., Jr. The efficacy and toxicity of bevacizumab in combination with gemcitabine in patients with recurrent ovarian Cancer. Clin. Ovarian Cancer 2011, 4, 34-37.

6. Colomer, R. Review of gemcitabine plus taxane combination therapy in the first-line treatment of metastatic breast cancer. Eur. J. Cancer Suppl. 2008, 6, 9-12.

7. Colomer, R. Gemcitabine plus taxane combinations in metastatic breast cancer: A comprehensive review. Eur. J. Cancer Suppl. 2005, 3, 9-16.

8. Makrantonakis, P.; Ziotopoulos, P.; Agelidou, A.; Polyzos, A.; Ziras, A.; Chandrinos, V.; Vossos, A.; Kalykaki, A.; Androulakis, N.; Geroyianni, A. Vinorelbine and cisplatin combination in pretreated patients with advanced non-small cell lung cancer pretreated with a taxane-based regimen: A multicenter phase II study. Lung Cancer 2006, 53, 85-90.

9. Pereira, J.R.; Fein, L.; del Giglio, A.; Blajman, C.R.; Richardet, E.; Schwartsmann, G.; Orlando, M.; Hall, B.J.; West, T.M.; van Kooten, M. Gemcitabine administered as a short infusion versus a fixed dose rate in combination with cisplatin for the treatment of patients with advanced non-small cell lung cancer. Lung Cancer 2007, 58, 80-87.

10. Scripture, C.D.; Figg, W.D. Drug interactions in cancer therapy. Nat. Rev. Cancer 2006, 6, 546-558.

11. Aird, R.; Cummings, J.; Ritchie, A.; Muir, M.; Morris, R.; Chen, H.; Sadler, P.; Jodrell, D. In vitro and in vivo activity and cross resistance profiles of novel ruthenium (II) organometallic arene complexes in human ovarian cancer. Br. J. Cancer 2002, 86, 1652-1657.

12. Tkaczuk, K.H.R. Review of the contemporary cytotoxic and biologic combinations available for the treatment of metastatic breast cancer. Clin. Ther. 2009, 31, 2273-2289.

13. Friedberg, J.W.; Neuberg, D.; Gribben, J.G.; Fisher, D.C.; Koval, M.; Poor, C.M.; Green, L.M.; Daley, J.; Soiffer, R.; Ritz, J. Combination immunotherapy with rituximab and interleukin 2 in patients with relapsed or refractory follicular non-Hodgkin's lymphoma. Br. J. Haematol. 2002, $117,828-834$. 
14. Pandey, S.; Murphy, R.F.; Agrawal, D.K. Recent advances in the immunobiology of ceramide. Exp. Mol. Pathol. 2007, 82, 298-309.

15. Vlerken, L.E.; Duan, Z.; Seiden, M.V.; Amiji, M.M. Modulation of intracellular ceramide using polymeric nanoparticles to overcome multidrug resistance in cancer. Cancer Res. 2007, 67, 4843-4850.

16. Taniguchi, M.; Okazaki, T. The role of sphingomyelin and sphingomyelin synthases in cell death, proliferation and migration-from cell and animal models to human disorders. Biochim. Biophys. Acta 2013, doi:10.1016/j.bbalip.2013.12.003.

17. Henry, B.; Möller, C.; Dimanche-Boitrel, M.T.; Gulbins, E.; Becker, K.A. Targeting the ceramide system in cancer. Cancer Lett. 2011, 332, 286-294.

18. Stover, T.; Kester, M. Liposomal delivery enhances short-chain ceramide-induced apoptosis of breast cancer cells. J. Pharmacol. Exp. Ther. 2003, 307, 468-475.

19. Haynes, T.A.S.; Filippov, V.; Filippova, M.; Yang, J.; Zhang, K.; Duerksen-Hughes, P.J. DNA damage induces down-regulation of UDP-glucose ceramide glucosyltransferase, increases ceramide levels and triggers apoptosis in p53-deficient cancer cells. Biochim. Biophys. Acta 2012, 1821, 943-953.

20. Itoh, M.; Kitano, T.; Watanabe, M.; Kondo, T.; Yabu, T.; Taguchi, Y.; Iwai, K.; Tashima, M.; Uchiyama, T.; Okazaki, T. Possible role of ceramide as an indicator of chemoresistance decrease of the ceramide content via activation of glucosylceramide synthase and sphingomyelin synthase in chemoresistant leukemia. Clin. Cancer Res. 2003, 9, 415-423.

21. Vlerken, L.E.; Duan, Z.; Little, S.R.; Seiden, M.V.; Amiji, M.M. Augmentation of therapeutic efficacy in drug-resistant tumor models using ceramide coadministration in temporal-controlled polymer-blend nanoparticle delivery systems. AAPS J. 2010, 12, 171-180.

22. Tallarida, R.J. Drug synergism: Its detection and applications. J. Pharmacol. Exp. Ther. 2001, 298, 865-872.

23. Pinato, D.J.; Graham, J.; Gabra, H.; Sharma, R. Evolving concepts in the management of drug resistant ovarian cancer: Dose dense chemotherapy and the reversal of clinical platinum resistance. Cancer Treat. Rev. 2013, 39, 153-160.

24. Kono, K.; Kojima, C.; Hayashi, N.; Nishisaka, E.; Kiura, K.; Watarai, S.; Harada, A. Preparation and cytotoxic activity of poly (ethylene glycol)-modified poly (amidoamine) dendrimers bearing adriamycin. Biomaterials 2008, 29, 1664-1675.

25. Liu, S.; Guo, Y.; Huang, R.; Li, J.; Huang, S.; Kuang, Y.; Han, L.; Jiang, C. Gene and doxorubicin co-delivery system for targeting therapy of glioma. Biomaterials 2012, 33, 4907-4916.

26. Chougule, M.; Patel, A.R.; Sachdeva, P.; Jackson, T.; Singh, M. Anticancer activity of Noscapine, an opioid alkaloid in combination with Cisplatin in human non-small cell lung cancer. Lung Cancer 2011, 71, 271-282.

27. Chou, T.C. Theoretical basis, experimental design, and computerized simulation of synergism and antagonism in drug combination studies. Pharmacol. Rev. 2006, 58, 621-681.

28. Lakhani, S.A.; Masud, A.; Kuida, K.; Porter, G.A.; Booth, C.J.; Mehal, W.Z.; Inayat, I.; Flavell, R.A. Caspases 3 and 7: Key mediators of mitochondrial events of apoptosis. Science 2006, 311, 847-851. 
29. Nehme, A.; Varadarajan, P.; Sellakumar, G.; Gerhold, M.; Niedner, H.; Zhang, Q.; Lin, X.; Christen, R. Modulation of docetaxel-induced apoptosis and cell cycle arrest by all-trans retinoic acid in prostate cancer cells. Br. J. Cancer 2001, 84, 1571-1576.

30. Louzao, M.C.; Ares, I.R.; Cagide, E.; Espiña, B.; Vilariño, N.; Alfonso, A.; Vieytes, M.R.; Botana, L.M. Palytoxins and cytoskeleton: An overview. Toxicon 2011, 57, 460-469.

31. Riedl, S.J.; Shi, Y. Molecular mechanisms of caspase regulation during apoptosis. Nat. Rev. Mol. Cell Biol. 2004, 5, 897-907.

32. Yang, Y.; Wang, J.; Zhang, X.; Lu, W.; Zhang, Q. A novel mixed micelle gel with thermo-sensitive property for the local delivery of docetaxel. J. Control. Release 2009, 135, 175-182.

33. Oh, K.T.; Lee, E.S.; Kim, D.; Bae, Y.H. L-histidine-based pH-sensitive anticancer drug carrier micelle: Reconstitution and brief evaluation of its systemic toxicity. Int. J. Pharm. 2008, 358, 177-183.

34. Chapman, J.V.; Gouazé-Andersson, V.; Messner, M.C.; Flowers, M.; Karimi, R.; Kester, M.; Barth, B.M.; Liu, X.; Liu, Y.Y.; Giuliano, A.E. Metabolism of short-chain ceramide by human cancer cells-Implications for therapeutic approaches. Biochem. Pharmacol. 2010, 80, 308-315.

35. Yang, X.; Li, Y.; Li, M.; Zhang, L.; Feng, L.; Zhang, N. Hyaluronic acid-coated nanostructured lipid carriers for targeting paclitaxel to cancer. Cancer Lett. 2013, 334, 338-345.

36. Liu, D.; Liu, F.; Liu, Z.; Wang, L.; Zhang, N. Tumor specific delivery and therapy by double-targeted nanostructured lipid carriers with anti-VEGFR-2 antibody. Mol. Pharm. 2011, 8, 2291-2301.

37. Montero, A.; Fossella, F.; Hortobagyi, G.; Valero, V. Docetaxel for treatment of solid tumours: A systematic review of clinical data. Lancet Oncol. 2005, 6, 229-239.

38. Hari, M.; Loganzo, F.; Annable, T.; Tan, X.; Musto, S.; Morilla, D.B.; Nettles, J.H.; Snyder, J.P.; Greenberger, L.M. Paclitaxel-resistant cells have a mutation in the paclitaxel-binding region of $\beta$-tubulin (Asp26Glu) and less stable microtubules. Mol. Cancer Ther. 2006, 5, 270-278.

39. Rao, J.; Li, N. Microfilament actin remodeling as a potential target for cancer drug development. Curr. Cancer Drug Targrts 2004, 4, 345-354.

40. Lindberg, U.; Karlsson, R.; Lassing, I.; Schutt, C.E.; Höglund, A.S. The microfilament system and malignancy. Semin. Cancer Biol. 2008, 18, 2-11.

41. Hayot, C.; Debeir, O.; van Ham, P.; van Damme, M.; Kiss, R.; Decaestecker, C. Characterization of the activities of actin-affecting drugs on tumor cell migration. Toxicol. Appl. Pharmacol. 2006, 211, 30-40.

42. Wang, J.; Lv, X.W.; Du, Y.G. Potential mechanisms involved in ceramide-induced apoptosis in human colon cancer HT29 cells. Biomed. Environ. Sci. 2009, 22, 76-85.

43. Wang, L.; Li, M.; Zhang, N. Folate-targeted docetaxel-lipid-based-nanosuspensions for active-targeted cancer therapy. Int. J. Nanomed. 2012, 7, 3281-3294.

44. Wang, L.; Liu, Z.; Liu, D.; Liu, C.; Juan, Z.; Zhang, N. Docetaxel-loaded-lipid-basednanosuspensions (DTX-LNS): Preparation, pharmacokinetics, tissue distribution and antitumor activity. Int. J. Pharm. 2011, 413, 194-201.

(C) 2014 by the authors; licensee MDPI, Basel, Switzerland. This article is an open access article distributed under the terms and conditions of the Creative Commons Attribution license (http://creativecommons.org/licenses/by/3.0/). 